\title{
Transport Models / Radionuclides
}

National Cancer Institute

\section{Source}

National Cancer Institute. Transport Models / Radionuclides. NCI Thesaurus. Code C19087.

The use of labelled tracers for the elucidation of transport pathways. 